\title{
Soil microbial community assemblage and its seasonal variability in alpine treeline ecotone on the eastern Qinghai-Tibet Plateau
}

\author{
Li Kui ${ }^{1}$, Hui Sun ${ }^{2, *}$, Qian Lei $^{2}$, Wei Gao ${ }^{3}$, Lijun Bao ${ }^{3}$, Yuexi Chen ${ }^{2}$, Zhongjun Jia ${ }^{3}$ \\ 1 Marine Science Institute, University of California, Santa Barbara, CA 93106, USA \\ 2 Department of Environmental Science and Engineering, Sichuan University, Chengdu 610065, China \\ 3 State Key Laboratory of Soil and Sustainable Agriculture, Institute of Soil Science, Chinese Academy of Sciences, Nanjing 210008, China
}

\section{ARTICLE INFO}

\section{Article history:}

Received June 18, 2018

Revised October 3, 2018

Accepted October 9, 2018

Keywords:

Alpine forest

Treeline ecotone

Soil microbial community

Stability

High-throughput sequencing

\begin{abstract}
A B S T R A C T
The alpine treeline ecotone is characterized as the upper limit of the forest in the high-mountain ecosystem. Due to the freeze-thaw cycles, the soil organism community, such as microbial communities are expected to change between seasons. However, there are limited microbialcommunity studies focused on the high altitude alpine ecosystem. We conducted a study in the alpine treeline ecotone on the eastern Qinghai-Tibet Plateau, China, and investigated the seasonal variability of the soil microbial community. We collected all soil samples within the alpine treeline ecotone, between the treeline and timberline in the high-mountain region. The 16S rRNA genes of the microbial communities (bacterial and archaeal) were analyzed by highthroughput sequencing to the genus level. The results showed that soil microbial community in the alpine treeline ecotone was consistently dominated by eight phyla which consisted of $95 \%$ of the total microbial community, including Proteobacteria, Actinobacteria, Acidobacteria, Firmicutes, Planctomycetes, Chloroflexi, Bacteroidetes, and Verrucomicrobia. The overall diversity and evenness of the community were relatively stable, with an average of $0.5 \%$ difference between seasons. The highest seasonal variability occurred at the upper boundary of the alpine treeline ecotone, and few or almost no seasonal change was observed at lower elevations, indicating dense forest cover and litter deposition might have created a local microclimate that reduced seasonal variation among the surrounding environmental conditions. Our study was one of the first group that documented the microbial community assemblage in the treeline ecotone on the Qinghai-Tibet Plateau.
\end{abstract}

(c) Higher Education Press 2019

\section{Introduction}

Microbes, the most abundant and diverse group of soil organism, play a fundamental role in the biosphere by regulating soil biogeochemical processes such as decomposition and nutrient transformation (Seastedt, 1984; Xiong

\footnotetext{
* Corresponding author

E-mail address: sunhuifiles@gmail.com (H. Sun)
}

et al., 2016). The speed and volume of the decomposition are positively driven by the diversity of the microbes in the soil (Gessner et al., 2010; Baumann et al., 2013). A high microbial diversity tends to speed up the organic matters' turnover rate and contribute a great amount of bio-available carbon and nitrogen for the surrounding living organisms such as plants and fungi (Bardgett et al., 2008; Supramaniam et al., 2016). In turn, a variety of environmental conditions, such as soil texture, soil moisture, precipitation, and vegetation community, have significant effects on microbial community diversity 
and assemblage. Research studying community assemblage and diversity under the different environmental conditions helps to predict the resilience and flexibility of the soil ecosystem.

The alpine treeline ecotone is defined as the upper limit of the forest in the high-mountain ecosystem. It is characterized as freeze-thaw cycles, high solar radiation, low nutrient supply, and limited water availability. In the treeline ecotone, vegetation community shifts from forest to shrub or even bare rock as the elevation increases. Along with an elevation gradient, the microbes' diversity and relative abundance could change (Deslippe et al., 2012; Buckeridge et al., 2013; Zhang et al., 2015). Because of the extreme environmental conditions and constrained niche for flora and fauna, any slight change in environment (e.g., climate regime) could induce ecosystem shift, such as species migration and replacement (Kupfer and Cairns, 1996; Liu et al., 2009). Recently, several studies that focused on the microbial community in alpine soils have suggested that the structure and activity of the microbial community varied among seasons and along an elevation gradient (Margesin et al., 2009; Lazzaro et al., 2015). Specifically, the timing and duration of the snow-melt have affected the diversity and abundance of the microbial community (Lipson et al., 2002; Zinger et al., 2009). All these interesting studies have been benefited from the modern molecular technologies. The techniques in the early time were insufficient to identify microbes to a high taxonomic resolution (e.g., genus), which made it difficult to draw a clear conclusion about diversity and abundance. Recently, the technologies have been improved, from the plate and direct counts followed by identification via typing methods (Vandamme et al., 1996; Johnsen et al., 2001) to molecular techniques involved extraction of nucleic acid and analysis of the base distribution of DNA (Torsvik et al., 1994). With the development of DNA-based analysis methods, researchers have identified the taxa to a much higher taxonomic resolution, which allows us to tackle more complicated research questions (Lipson and Schmidt, 2004; Smith et al., 2006; Chu et al., 2010).

Our study was conducted in an alpine treeline ecotone on the Qinghai-Tibet Plateau in western Sichuan, China. Within an approx. $250000 \mathrm{~km}^{2}$ mountain range, only a handful of microbial community studies have been carried out over the past five years, and most of them were implemented below the treeline at low elevations. We were one of the first group that had worked on the treeline ecotone and assessed the soil microbial diversity. Our objective was to document the soil microbial community structure, including taxa diversity and seasonal variability. The research questions were: 1) What microbial species were present in the alpine treeline ecotone? 2) How diverse was the microbial community? 3) What was the seasonal variability of the community assemblage?

\section{Materials and methods}

We collected soil samples in the alpine treeline ecotone on the
Qinghai-Tibet Plateau, and identified the soil microbes using high-throughput $16 \mathrm{~S}$ rRNA sequencing. The microbial community diversity indices were calculated, and the seasonal variability was examined.

\subsection{Site descriptions}

Soil samples were collected in Mt. Mengbi, Sichuan Province, China. The mountain is located at the east edge of the Qinghai-Tibet Plateau, and it connects to the Qionglai Mountains and Daxue Mountains. Mt. Mengbi has a mountainous monsoon season with a cool-rainy summer and cold-dry winter. Surface soil $(0-40 \mathrm{~cm})$ within our sampling region is typically frozen from October to May (Table 1).

The soil sampling location was nearby the coordinate $31.51^{\circ} \mathrm{N}$ and $102.35^{\circ} \mathrm{E}$, where the elevation of the alpine treeline ecotone ranged between $4000 \mathrm{~m}$ and $4200 \mathrm{~m}$. We set up three sampling zones that covered the treeline (AT, the upper boundary of the treeline ecotone), the timberline (TL, the low boundary), and the area between AT and TL (RC, midelevation) (Table 1, Fig. 1). The alpine treeline ecotone was covered by conifer forest with dominant species of Abies faxoniana and Picea balfouriana. The soil texture was organic loamy sand, classified as mountain brown coniferous forest soil (Gong et al., 1978).

\subsection{Soil sample collections}

In August 2013 (warm season) and April 2014 (cold season), two sampling events took place over a period of 7 days each time, and a total of 18 soil samples were collected. In each sampling event, we harvested three individual soil samples from the topsoil ( $20 \mathrm{~cm}$ in depth) in each of the three sampling zones (AT, RC, and TL). In April, the soil was frozen when we dug up the samples. Sampling locations were placed along the contour line and approx. $40 \mathrm{~m}$ away from each other. In the laboratory, the three samples from the same zone were mixed homogeneously and combined into one sample for soil physical characteristics analysis, DNA extractions, and pyrosequencing.

A subset of the soil from each sample was taken out to analyze the $\mathrm{pH}$, organic carbon, and nitrogen content. Each of these samples was run through a sequence of sieves that were $0.02 \mathrm{~mm}, 0.05 \mathrm{~mm}, 0.25 \mathrm{~mm}$, and $2 \mathrm{~mm}$, and the carbon and nitrogen analyses were done on the soils sorted in each of these four size bins (Table 1).

\subsection{DNA extraction and pyrosequencing}

Six soil samples ( 3 sampling zones $\times 2$ seasons) for the DNA sequencing were sieved through a 2-mm mesh screen to remove gravel, litter, and fine roots. Then the samples were sent to the State Key Laboratory of Soil and Sustainable Agriculture Institute of Soil Science (Nanjing, China) for 16S rRNA extraction and classification. To extract rRNA, a $0.5 \mathrm{~g}$ fresh soil from each sample was diluted in acidic lysis buffer for cell lysis, supernatant was extracted from the solution, 


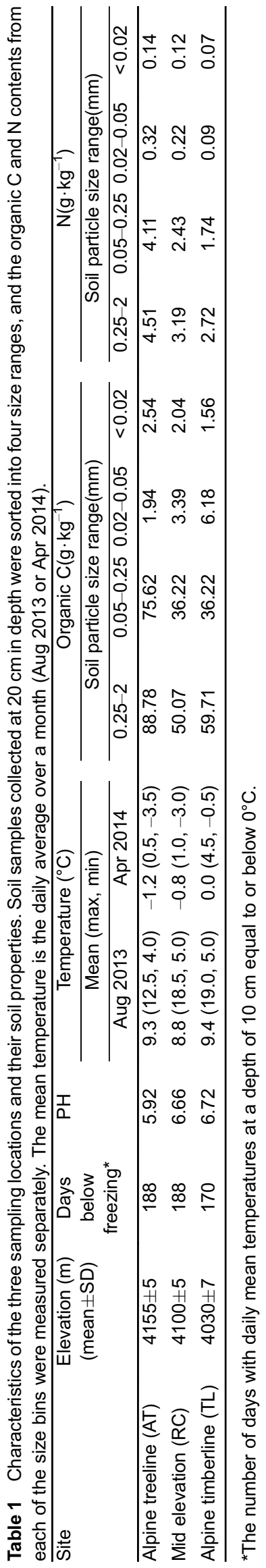




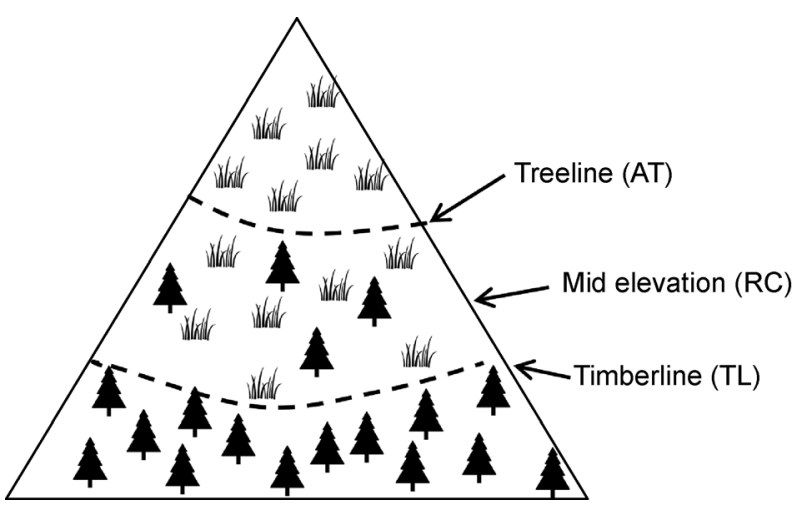

Fig. 1 Schematic diagram presented an alpine treeline ecotone constrained between treeline and timberline in high-mountain ecosystems. The soil sampling sites were located the upper $(\mathrm{AT})$, lower ( $\mathrm{TL})$, and mid-elevation $(\mathrm{RC})$ of the alpine treeline transition zone.

nucleic acids were precipitated and purified via Polymerase Chain Reaction amplification using the forward primer $515 \mathrm{~F}$ and the reverse primer 907R which was targeted to identify bacterial and archaeal taxa groups (Angenent et al., 2005; Xia et al., 2011).

The purified amplicons were sent to high-throughput sequencing on a Roche 454 pyrosequencer, and data were processed in the Quantitative Insights into Microbial Ecology (QIIME version: 1.9.1) pipeline (http://qiime.org/). After removing the low-quality sequences and assigned sequence reads to the corresponding samples, we extracted the $\mathrm{V} 4 \mathrm{~V} \mathrm{~V} 5$ region of the sequences and clustered them into Operational Taxonomic Units (OTUs) at a $97 \%$ sequences identity. The representative sequence from each OUT was selected for taxonomic identification to the genus level using Ribosomal Database Project (RDP) classifier (http://rdp.cme.msu.edu/) (Huse et al., 2007; Nawrocki and Eddy, 2007; Cole et al., 2009). The detailed experiment setting and chemical used for DNA extraction and purification during pyrosequencing can refer to
Xia et al. (2011). The raw sequences were archived into the NCBI Sequence Read Archive (https://www.ncbi.nlm.nih.gov/) under accession number SRP100406.

We calculated the overall microbial diversity at different elevations over two seasons using diversity indices: richness, Shannon-Wiener index, and Simpson's index. The diversity indices were calculated at the order level because "order" was the optimal taxonomic rank in our study (details were discussed in the results section and Table 2). All the analyses were performed in $R$ language ( $R$ Core Team, 2016). Richness was computed by summing up the number of present taxa. Shannon and Simpson's indices were computed using the diversity() function of the "vegan" package based on taxa's relative abundance.

\section{Results}

\subsection{The composition of soil microbial community}

In the soil samples from 2013 summer and 2014 winter, there were a total of 19722 high-quality DNA reads, with $3287 \pm$ 1226 (mean \pm SD) DNA read from each sample. The bacterial community consisted of $99 \%$ of the reads, whereas the archaeal was $\sim 0.3 \%$, and other $0.6 \%$ unidentified reads.

All identified reads were grouped into 32 phyla, with 13 phyla present in all samples (Table 2). Among these common phyla, eight of them constituted $95 \%$ of the total population. Total of Proteobacteria and Actinobacteria was $~ 53.4 \%$, followed by Acidobacteria, Firmicutes, Planctomycetes, Chloroflexi, Bacteroidetes, and Verrucomicrobia that accounted for $13.3 \%, 9.7 \%, 8 \%, 4.4 \%, 3.8 \%$ and $2.4 \%$ of the population, respectively (Fig. 2). Other common phyla, including Gemmatimonadetes, Nitrospirae, Elusimicrobia, Armatimonadetes, and Cyanobacteria were less than $5 \%$ of the total population. Among all 32 phyla, $78 \%$ of the taxa (25 phyla) presented in both warm and cold seasons (at least appeared in one sample in each season). There were two phyla, FCPU426 $(0.03 \%)$ and Euryarchaeota $(0.1 \%)$ that only

Table 2 The relative abundance of the identified taxa (ID-taxa) and unidentified taxa (other) in each sample, as well as the number of identified taxa in each taxonomic group.

\begin{tabular}{|c|c|c|c|c|c|c|c|c|c|}
\hline & & ATw & ATc & $\mathrm{RCw}$ & $\mathrm{RCc}$ & TLW & TLC & Mean percent & \# of taxa group \\
\hline \multirow[t]{2}{*}{ Genus } & Other & 45.6 & 77.7 & 76.9 & 80 & 68.3 & 75 & 70.6 & \\
\hline & ID-taxa & 54.4 & 22.3 & 23.1 & 20 & 31.7 & 25 & 29.4 & 132 \\
\hline \multirow[t]{2}{*}{ Family } & Other & 17.4 & 38.3 & 39.7 & 30.9 & 28.4 & 34.8 & 31.6 & \\
\hline & ID-taxa & 82.6 & 61.7 & 60.3 & 69.1 & 71.6 & 65.2 & 68.4 & 136 \\
\hline \multirow[t]{2}{*}{ Order } & Other & 3.1 & 8.9 & 7.1 & 5.2 & 6.1 & 7.1 & 6.3 & \\
\hline & ID-taxa & 96.9 & 91.1 & 92.9 & 94.8 & 93.9 & 92.9 & 93.7 & 129 \\
\hline \multirow[t]{2}{*}{ Class } & Other & 1.4 & 0.7 & 0.9 & 1.2 & 1.9 & 0.9 & 1.1 & \\
\hline & ID-taxa & 98.6 & 99.3 & 99.1 & 98.8 & 98.1 & 99.1 & 98.9 & 94 \\
\hline \multirow[t]{2}{*}{ Phylum } & Other & 0.8 & 0.4 & 0.4 & 0.6 & 1.4 & 0.4 & 0.7 & \\
\hline & ID-taxa & 99.2 & 99.6 & 99.6 & 99.4 & 98.6 & 99.6 & 99.3 & 32 \\
\hline \multirow[t]{2}{*}{ Kingdom } & other & 0.8 & 0.4 & 0.3 & 0.6 & 1.4 & 0.3 & 0.6 & \\
\hline & ID-taxa & 99.2 & 99.6 & 99.7 & 99.4 & 98.6 & 99.7 & 99.4 & 2 \\
\hline
\end{tabular}

Note: The microbial taxa in our soil samples had the optimal resolution at the "order" with an average of $94 \%$ taxa identified to 129 orders. 


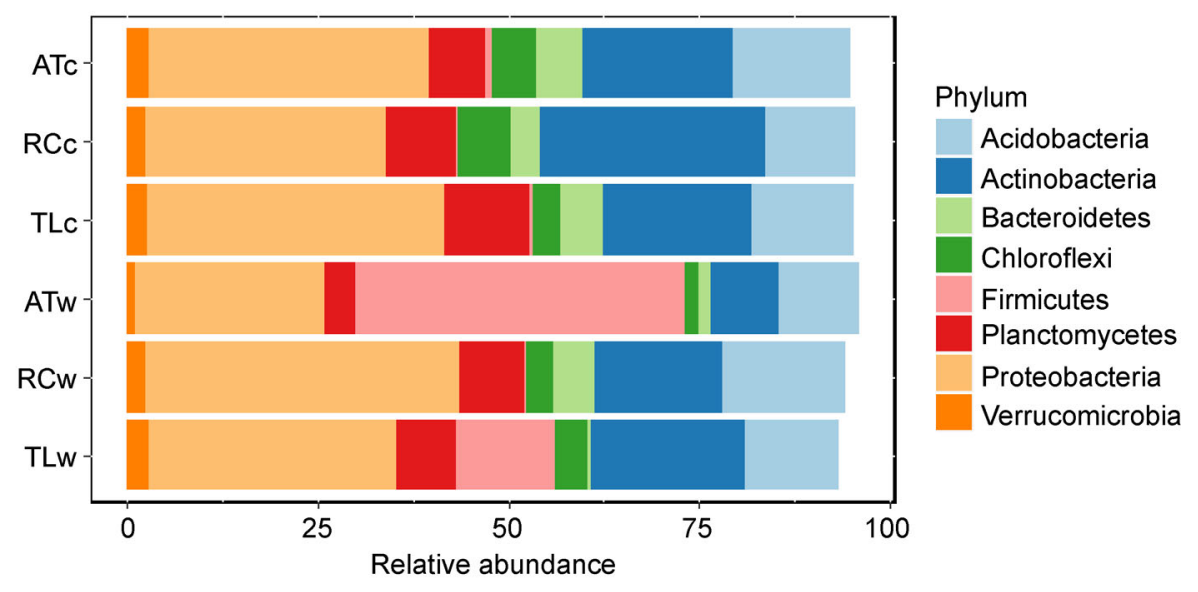

Fig. 2 Microbial communities in alpine treeline ecotone soils in warm (w) and cold (c) seasons. The figure shows only 8 phyla consisted of $95 \%$ of the community. The AT stands for alpine treeline, TL is alpine timberline, and RC is mid-elevation zone between AT and TL.

appeared in the summer warm season, and five phyla, OP11 (0.04\%), FBP (0.02\%), BHI80-139 (0.02\%), NKB19 (0.04\%), and Tenericutes $(0.02 \%)$ were only present in the winter cold season. Total percent of these seasonal-specific phyla were less than $1 \%$ of the total population.

As the taxonomic resolution increased from the rank of the phylum to genus, there were fewer taxa identified, from $99.3 \%$ at phylum to $29.4 \%$ at the genus level (Table 2). Among the taxa groups at the genus level, Bacillus was the most abundant one (32\%), especially at the higher elevation (AT) and in the summer season (Fig. 3). The following dominant species Rhodoplanes, Bradyrhizobium, DA101, Alicyclobacillus had the relative abundance of $4.5 \%, 2.7 \%, 1.2 \%$, and $0.9 \%$, respectively. Among 132 identified genera, 24 species $(19 \%)$ were recorded in all samples, and $18(14 \%)$ appeared in five of the six samples. There were 38 species (29\%), e.g., Acidiphilium, Acidocella, Actinomycetospora, and Aeromicrobium were present in one of the six samples, indicating that the niche for these species was small in the alpine treeline region.

There were $94 \%$ of the taxa identified at the rank of order. Every soil sample had more than $90 \%$ of taxa identified at the order level. The identified taxa at the order were $25 \%$ more than the family, and $63 \%$ more than the genus (Table 2). Because "order" had a higher taxonomic resolution (better than class, phylum, and kingdom) and a better representation of the community (94\%), we used it in the following diversity analyses.

3.2 Biodiversity and seasonal variability of soil microbial community

The microbial diversities were relatively stable in the alpine treeline ecotone (Table 3). Among all samples, taxa richness was between 70 to 93 across all sites, with the seasonal differences ranged from 1 and 19 (Table 3). The Shannon and Simpson indices, measurements of diversity accounted for the number of species present and the relative abundance of

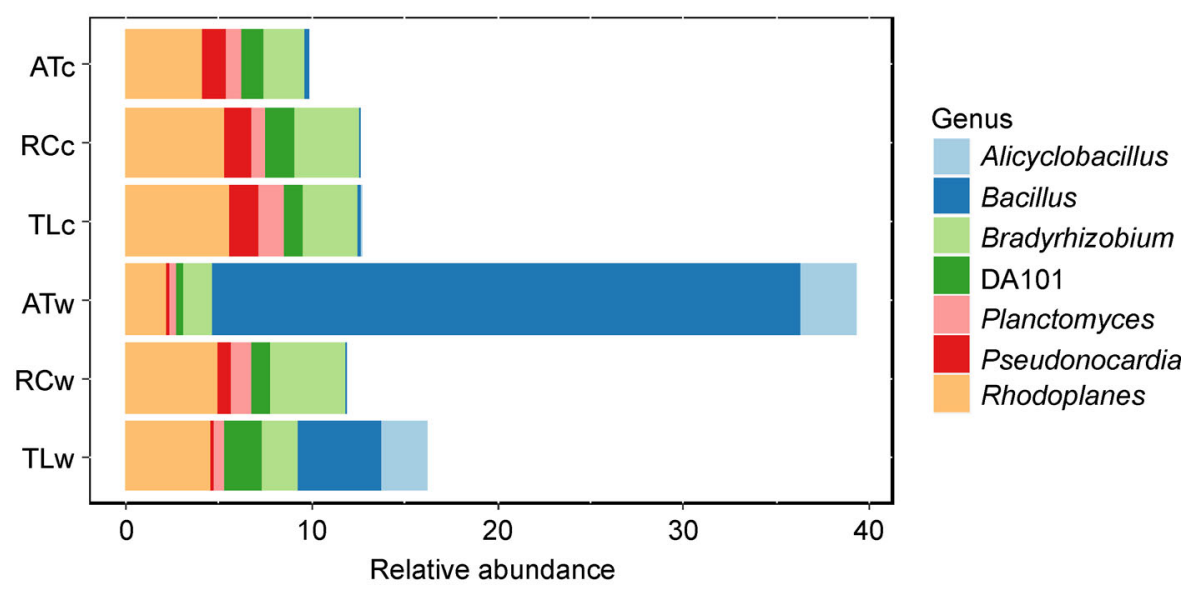

Fig. 3 The relative abundance of top 7 identified genera in alpine treeline ecotone between the warm (w) and cold (c) seasons. The unclassified genera (mainly the white space) consisted of between $45 \%$ to $77 \%$ of the microbial community. The AT stands for alpine treeline, $\mathrm{TL}$ is alpine timberline, and RC is mid-elevation zone between AT and TL. 
Table 3 Soil microbial Operational Taxonomic Units (OUT) and diversity indices based on the taxonomy at the order level. The seasonal variability was greatest at the highest elevation.

\begin{tabular}{|c|c|c|c|c|c|c|}
\hline \multirow{2}{*}{$\begin{array}{l}\text { Site } \\
\text { Season }\end{array}$} & \multicolumn{2}{|c|}{ Alpine treeline (AT) } & \multicolumn{2}{|c|}{ Mid elevation (RC) } & \multicolumn{2}{|c|}{ Alpine timberline (TL) } \\
\hline & Warm & Cold & Warm & Cold & Warm & Cold \\
\hline$\overline{\text { OTU }}$ & 560 & 1103 & 1404 & 1494 & 1327 & 1549 \\
\hline Richness & 70 & 89 & 90 & 89 & 85 & 93 \\
\hline Shannon index & 2.66 & 3.54 & 3.52 & 3.30 & 3.42 & 3.43 \\
\hline Simpson index & 0.81 & 0.95 & 0.95 & 0.94 & 0.95 & 0.95 \\
\hline
\end{tabular}

each species, had almost no change at TL (Table 3). The small changes in species richness and few/no change of the Shannon and Simpson indices suggested that there was a steady group of dominant species at the mid-elevation and the lower boundary of the treeline ecotone, and their relative abundance was stable between seasons.

Although the overall community assemblage was relative stable, there was some seasonal variability, with the largest seasonal variation occurred at the AT location. The richness and Shannon index at AT increased by $\sim 30 \%$, indicating a more sensitive microbial community at the upper treeline ecotone. At the phylum level, the relative abundance of the dominant taxa, Proteobacteria and Actinobacteria, increased up to $15 \%$ from summer to winter across all sites (Fig. 2). Oppositely, Firmicutes had the highest abundance in summer, and it was 35 times greater compared to the winter. The biggest seasonal increment for Firmicutes was observed at the AT site from winter to summer, primarily because of a great increase in genus Bacillus which consisted of $32 \%$ of the microbial population (Fig. 3).

Among the top 9 taxonomic groups at the order level, the magnitude and direction of the seasonal variabilities changed among individual taxa (Fig. 4). The seasonal difference in relative abundance across all taxa groups was $0.56 \% \pm 2.3 \%$ (mean \pm SD), whereas the elevation difference within a season was $1.2 \% \pm 3.9 \%$. Although the elevation variability was slightly greater than the seasonal variability, they were not different from 0 . Thus, there was no consistent pattern across all taxa regarding the magnitude and direction of changes. As shown in Fig. 4, Actinomycetales, Gaiellales, Gemmatales, and Rhizobiales might prefer a cold season but Bacillales preferred a warm season.
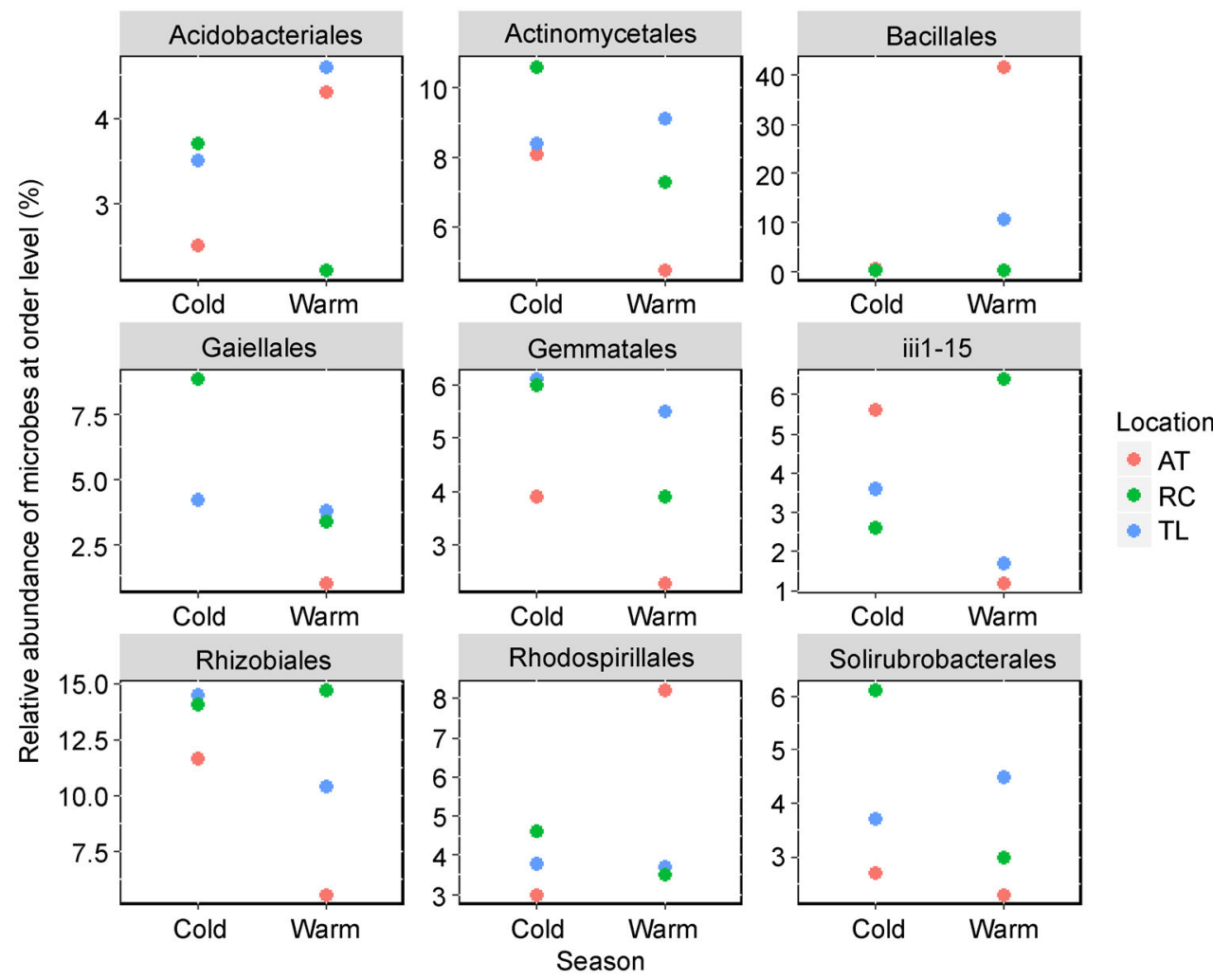

Fig. 4 The relative abundance of the top 9 microbial groups at the order level. The magnitude and direction of the seasonal effects were different among taxa. 


\section{Discussion}

Using high-throughput sequencing technology, we were able to identify taxa to the genus that allowed us to demonstrate the microbial community assemblage (mainly bacterial) in the alpine treeline ecotone and its seasonal variability. Surprisingly, compared to approximate 21 phyla in polar regions and 16 phyla in low-elevation alpine soils (Aislabie et al., 2008; Niederberger et al., 2008; Chu et al., 2010; Lynch et al., 2012), our study found a greater overall richness with 32 phyla in the alpine treeline ecotone. The majority ( 95\%) of soil microbial phyla were constantly present across seasons. Although $22 \%$ of the phyla were unique to a particular season, these phyla only consisted of less than $1 \%$ of the population, suggesting that the presence-absence of microbial species in our study region was relatively steady.

Thirteen common phyla groups, more than $95 \%$ of the microbial population, included Proteobacteria, Actinobacteria, Acidobacteria, Firmicutes, Planctomycetes, Chloroflexi, Bacteroidetes, Verrucomicrobia, Gemmatimonadetes, Nitrospirae, Elusimicrobia, Armatimonadetes, and Cyanobacteria. Because of a stable species richness and evenness in the microbial community observed in our study, we do not expect big changes occurred in the microbial community over time. Similar results were shown in other studies where researchers suggested that these stable microbial communities had high environmental resilience (Supramaniam et al., 2016). The dominant microbial groups found in our study were not only present in the alpine region, but also dominated the permafrost and seasonally frozen ground (Zhou et al., 1997; Nemergut et al., 2005; Janssen, 2006; Fierer et al., 2012). The consistency of soil microbial phylogenetic structure across varieties of ecosystems has further confirmed a hypothesis proposed by a recent study in Chu's group that microbial communities in the globe might have a similar assemblage (Chu et al., 2010)

Among the taxa observed in our study area, approx. $1 \%$ had changed or replaced across sites and seasons, with more winter-specific taxa (five phyla) than the summer ones (two phyla). The studies on species replacement (also called species turnover) between seasons suggested that some microbes were only adaptable to certain ranges of temperature, soil moisture, or vegetation types (Zhou et al., 1997; Legendre, 2014). Although the occupancy percent was relatively small for these seasonally specific taxa groups, the existence of these phyla might have played some important roles in soil decomposition process that deserves further studies.

Although the presence-absence of the dominant taxa was relatively stable, there was a seasonal variability at the upper boundary of the treeline ecotone. The greatest seasonal variation occurred in Proteobacteria, Firmicutes (mainly genus Bacillus) and Actinobacteria at AT, which might due to a strong contrast on the temperature, from frozen soil in winter to warm bare soil surface in summer. At lower elevations, the environmental conditions changed relatively moderate between seasons due to various reasons such as vegetation cover and litter deposition. The local environment typically has a high soil moisture content that could reduce the daily or seasonal soil temperature fluctuation and creates a local micro-climate for the organisms. As a result, the microbial community's diversity had almost no change at the low boundary of the treeline ecotone (Aislabie et al., 2008; Chu et al., 2010). A study focused on the alpine region of the Colorado Rocky Mountain had found a significant relationship between the bacterial community structure and the temperature fluctuation (Lipson, 2007). However, the effects of temperature on different taxonomic groups are varied. For example, Firmicutes had a relatively high abundance in summer compared to the winter but Acidobacteria was the opposite (Supramaniam et al., 2016). The species that preferred the cold weather were typically characterized by some cold resistant mechanisms, including a decline in enzyme activity, a decrease in membrane fluidity, lower rates of transcription, and reduction in translation and cell division (D'Amico et al., 2006). The lower abundance of the Firmicutes in winter time was probably due to the activity inhibition in the cold weather, which was consistent with a study in Antarctic cold deserts and an Alaska boreal forest soil (Fierer et al., 2012). The microbial community diversity had a slight increase in winter which was different from the other studies such as a laboratory experiment implemented by Castro et al. (2010). One explanation could be that the laboratory study did not mimic other environmental variables such as vegetation cover that was embedded in our field study. The combination of multiple physical factors might have balanced out or even out-weighted the temperature effect (Schadt et al., 2003; Dilly et al., 2004; Lazzaro et al., 2011). With our limited sample size, we were not able to statistically determine the contribution and magnitude of the environmental variables on microbial assemblage, which certainly should be pursued in depth in future studies.

Our findings provided insights that the soil microbes, particularly bacterial, in alpine treeline ecotone were relatively stable. In the context of global climate change, the QinghaiTibetan Plateau is expected to have rising temperatures in alpine treeline ecotone (Beniston, 2003; Kullman, 2004; Green and Pickering, 2009; Myhre et al., 2013; Pachauri et al., 2014). Because the dominant taxa in the bacterial community were found relatively similar, a minor increment in the annual temperature is not expected to trigger a significant shift in the microbial community. In a warm year, a few cold-season taxa might be absent, but there will be other warm-season taxa that could fill in the niche and continue the soil decomposition processes. Other than the temperature, climate change could also result in changes in precipitation, soil moisture, nutrient flow, greenhouse gas concentration, plant-soil relationships (Heal, 1999; Castro et al., 2010; Gessner et al., 2010), as well as seasonal variations on the litter quality (Dilly et al., 2004). As the climate change issue becomes more recognizable to the world, we believe that more soil studies will be conducted on the Qinghai-Tibet 
Plateau, especially focusing on the interactions between environment drivers and microbial community. Our study provided the first-hand documentation on bacterial community assemblage and its seasonal variability in the region.

\section{Acknowledgments}

This study was funded by the National Natural Science Foundation of China (NSFC, No. 41271094 and No. 40871124).

\section{References}

Aislabie, J.M., Jordan, S., Barker, G.M., 2008. Relation between soil classification and bacterial diversity in soils of the Ross Sea region, Antarctica. Geoderma 144, 9-20.

Angenent, L.T., Kelley, S.T., St Amand, A., Pace, N.R., Hernandez, M. T., 2005. Molecular identification of potential pathogens in water and air of a hospital therapy pool. Proceedings of the National Academy of Sciences of the United States of America 102, 48604865.

Bardgett, R.D., Freeman, C., Ostle, N.J., 2008. Microbial contributions to climate change through carbon cycle feedbacks. ISME Journal 2, 805-814.

Baumann, K., Dignac, M.F., Rumpel, C., Bardoux, G., Sarr, A., Steffens, M., Maron, P.A., 2013. Soil microbial diversity affects soil organic matter decomposition in a silty grassland soil. Biogeochemistry 114, 201-212.

Beniston, M., 2003. Climatic change in mountain regions: A review of possible impacts. Climatic Change 59, 5-31.

Buckeridge, K.M., Banerjee, S., Siciliano, S.D., Grogan, P., 2013. The seasonal pattern of soil microbial community structure in mesic low arctic tundra. Soil Biology \& Biochemistry 65, 338-347.

Castro, H.F., Classen, A.T., Austin, E.E., Norby, R.J., Schadt, C.W., 2010. Soil microbial community responses to multiple experimental climate change drivers. Applied and Environmental Microbiology $76,999-1007$.

Chu, H., Fierer, N., Lauber, C.L., Caporaso, J.G., Knight, R., Grogan, P., 2010. Soil bacterial diversity in the Arctic is not fundamentally different from that found in other biomes. Environmental Microbiology 12, 2998-3006.

Cole, J.R., Wang, Q., Cardenas, E., Fish, J., Chai, B., Farris, R.J., Kulam-Syed-Mohideen, A.S., McGarrell, D.M., Marsh, T., Garrity, G.M., Tiedje, J.M., 2009. The Ribosomal Database Project: improved alignments and new tools for rRNA analysis. Nucleic Acids Research 37, D141-D145.

D’Amico, S., Collins, T., Marx, J.C., Feller, G., Gerday, C., 2006. Psychrophilic microorganisms: challenges for life. EMBO Reports 7, 385-389.

Deslippe, J.R., Hartmann, M., Simard, S.W., Mohn, W.W., 2012. Longterm warming alters the composition of Arctic soil microbial communities. FEMS Microbiology Ecology 82, 303-315.

Dilly, O., Bloem, J., Vos, A., Munch, J.C., 2004. Bacterial diversity in agricultural soils during litter decomposition. Applied and Environmental Microbiology 70, 468-474.

Fierer, N., Leff, J.W., Adams, B.J., Nielsen, U.N., Bates, S.T., Lauber,
C.L., Owens, S., Gilbert, J.A., Wall, D.H., Caporaso, J.G., 2012. Cross-biome metagenomic analyses of soil microbial communities and their functional attributes. Proceedings of the National Academy of Sciences of the United States of America 109, 21390-21395.

Gessner, M.O., Swan, C.M., Dang, C.K., McKie, B.G., Bardgett, R.D., Wall, D.H., Hättenschwiler, S., 2010. Diversity meets decomposition. Trends in Ecology \& Evolution 25, 372-380.

Gong, Z.T., Zhao, Q.G., Zeng, S.Z., 1978. A Drafting Proposal for Soil Classification of China. Soil (Göttingen) 10, 168-169.

Green, K., Pickering, C.M., 2009. The Decline of Snowpatches in the Snowy Mountains of Australia: Importance of Climate Warming, Variable Snow, and Wind. Arctic, Antarctic, and Alpine Research 41, 212-218.

Heal, O.W., 1999. Looking North: Current issues in Arctic soil ecology. Applied Soil Ecology 11, 107-109.

Huse, S.M., Huber, J.A., Morrison, H.G., Sogin, M.L., Welch, D.M., 2007. Accuracy and quality of massively parallel DNA pyrosequencing. Genome Biology 8, R143.

Janssen, P.H., 2006. Identifying the dominant soil bacterial taxa in libraries of $16 \mathrm{~S}$ rRNA and 16S rRNA genes. Applied and Environmental Microbiology 72, 1719-1728.

Johnsen, K., Jacobsen, C.S., Torsvik, V., Sørensen, J., 2001. Pesticide effects on bacterial diversity in agricultural soils-a review. Biology and Fertility of Soils 33, 443-453.

Kullman, L., 2004. The changing face of the alpine world. Global Change Newsletter 57, 12-14.

Kupfer, J.A., Cairns, D.M., 1996. The suitability of montane ecotones as indicators of global climatic change. Progress in Physical Geography: Earth and Environment 20, 253-272.

Lazzaro, A., Gauer, A., Zeyer, J., 2011. Field-scale transplantation experiment to investigate structures of soil bacterial communities at pioneering sites. Applied and Environmental Microbiology 77, 8241-8248.

Lazzaro, A., Hilfiker, D., Zeyer, J., 2015. Structures of microbial communities in alpine soils: seasonal and elevational effects. Frontiers in Microbiology 6, 1330.

Legendre, P., 2014. Interpreting the replacement and richness difference components of beta diversity. Global Ecology and Biogeography 23, 1324-1334.

Lipson, D.A., 2007. Relationships between temperature responses and bacterial community structure along seasonal and altitudinal gradients. FEMS Microbiology Ecology 59, 418 427.

Lipson, D.A., Schadt, C.W., Schmidt, S.K., 2002. Changes in soil microbial community structure and function in an alpine dry meadow following spring snow melt. Microbial Ecology 43, 307314.

Lipson, D.A., Schmidt, S.K., 2004. Seasonal changes in an alpine soil bacterial community in the colorado rocky mountains. Applied and Environmental Microbiology 70, 2867-2879.

Liu, Y., Zhang, J., Yang, W., 2009. Responses of alpine biodiversity to climate change. Shengwu Duoyangxing 17, 88-96.

Lynch, R., King, A., Farías, M.E., Sowell, P., Vitry, C., Schmidt, S., 2012. The potential for microbial life in the highest-elevation (>6000 masl) mineral soils of the Atacama region. Journal of Geophysical Research. Biogeosciences, 117. 
Margesin, R., Jud, M., Tscherko, D., Schinner, F., 2009. Microbial communities and activities in alpine and subalpine soils. FEMS Microbiology Ecology 67, 208-218.

Myhre, G., Shindell, D., Bréon, F., Collins, W., Fuglestvedt, J., Huang, J., Koch, D., Lamarque, J., Lee, D., Mendoza, B., 2013. Climatic Change 2013: The physical science basis. Contribution of Working Group I to the fifth assessment report of the intergovernmental panel on climate change. K., Tignor, M., Allen, SK, Boschung, J., Nauels, A., Xia, Y., Bex, V., and Midgley, PM, Cambridge University Press Cambridge, United Kingdom and New York, NY, USA.

Nawrocki, E.P., Eddy, S.R., 2007. Query-dependent banding (QDB) for faster RNA similarity searches. PLoS Computational Biology 3 , e56.

Nemergut, D.R., Costello, E.K., Meyer, A.F., Pescador, M.Y., Weintraub, M.N., Schmidt, S.K., 2005. Structure and function of alpine and arctic soil microbial communities. Research in Microbiology 156, 775-784.

Niederberger, T.D., McDonald, I.R., Hacker, A.L., Soo, R.M., Barrett, J.E., Wall, D.H., Cary, S.C., 2008. Microbial community composition in soils of Northern Victoria Land, Antarctica. Environmental Microbiology 10, 1713-1724.

Pachauri, R.K., Allen, M.R., Barros, V., Broome, J., Cramer, W., Christ, R., Church, J., Clarke, L., Dahe, Q., Dasgupta, P., 2014. Climatic Change2014: Synthesis Report. Contribution of working groups I, II and III to the fifth assessment report of the intergovernmental panel on climate change. IPCC.

R Core Team, 2016. R: A language and environment for statistical computing. R Foundation for Statistical Computing, Vienna, Austria. 2013. ISBN 3-900051-07-0.

Schadt, C.W., Martin, A.P., Lipson, D.A., Schmidt, S.K., 2003. Seasonal dynamics of previously unknown fungal lineages in tundra soils. Science 301, 1359-1361.

Seastedt, T., 1984. The role of microarthropods in decomposition and mineralization processes. Annual Review of Entomology 29, 25 46.
Smith, J.J., Tow, L.A., Stafford, W., Cary, C., Cowan, D.A., 2006. Bacterial diversity in three different Antarctic Cold Desert mineral soils. Microbial Ecology 51, 413-421.

Supramaniam, Y., Chong, C.W., Silvaraj, S., Tan, I.K.P., 2016. Effect of short term variation in temperature and water content on the bacterial community in a tropical soil. Applied Soil Ecology 107, 279-289.

Torsvik, V.L., Goksoyr, J., Daae, F.L., Sørheim, R., Michalsen, J., Salte, K., 1994. Beyond the Biomass: Compositional and Functional Analysis of Soil Microbial Communities. Pages 39-48 in Ritz, K., Dighton, J., Giller, K.E., editors. Beyond the Biomass: Compositional and Functional Analysis of Soil Microbial Communities. John Wiley \& Sons, New York.

Vandamme, P., Pot, B., Gillis, M., de Vos, P., Kersters, K., Swings, J., 1996. Polyphasic taxonomy, a consensus approach to bacterial systematics. Microbiological Reviews 60, 407-438.

Xia, W., Zhang, C., Zeng, X., Feng, Y., Weng, J., Lin, X., Zhu, J., Xiong, Z., Xu, J., Cai, Z., Jia, Z., 2011. Autotrophic growth of nitrifying community in an agricultural soil. ISME Journal 5, 12261236.

Xiong, Q., Pan, K., Zhang, L., Wang, Y., Li, W., He, X., Luo, H., 2016. Warming and nitrogen deposition are interactive in shaping surface soil microbial communities near the alpine timberline zone on the eastern Qinghai-Tibet Plateau, southwestern China. Applied Soil Ecology 101, 72-83.

Zhang, L., Yang, W., Wu, F., Xu, Z., Tan, B., Liu, Y., Wang, A., He, W., 2015. Soil microbe responses to seasonal freeze-thaw in the subalpine/alpine forests of western Sichuan. Chinese Journal of Applied and Environmental Biology 21, 505-511.

Zhou, J., Davey, M.E., Figueras, J.B., Rivkina, E., Gilichinsky, D., Tiedje, J.M., 1997. Phylogenetic diversity of a bacterial community determined from Siberian tundra soil DNA. Microbiology 143, 3913-3919.

Zinger, L., Shahnavaz, B., Baptist, F., Geremia, R.A., Choler, P., 2009. Microbial diversity in alpine tundra soils correlates with snow cover dynamics. ISME Journal 3, 850-859. 